\title{
WATER ACTIVITY CONCEPT AND ITS ROLE IN STRAWBERRIES FOOD
}

\author{
Elisaveta I. Sandulachi*, Pavel Gh.Tatarov \\ Techical University of Moldova, Chisinau, R. Moldova, \\ *e-mail: luiza_sandulachi@yahoo.com; tel. (+37322-509958); fax. (+37322-509960)
}

\begin{abstract}
This paper presents the study information related to the processing of fruit by combined methods. Is presented on the concept of water activity and its role in product quality; mathematical modeling methods (GAB, BET et al.) in estimate the activity coefficients of non-electrolyte and electrolyte mixture. Have been carried experimental research to study the evolution of the biologically active substances in frozen strawberries with and without sugar addition. It proved that frozen strawberries with sugar, during storage are more stable regarding antioxidants content that strawberry frozen without sugar.
\end{abstract}

Keywords: water activity, frozen strawerries, sugar addition, processing, osmotic treatment, stability.

\section{Introduction}

Quality and food security depends on $\mathrm{pH}$ and water activity $\left(\mathrm{a}_{\mathrm{w}}\right)$ in food environment. Foods with water activity are perishable. Water activity, $\mathrm{pH}$, temperature, and other parameters, have a direct impact on the growth of microorganisms, thus $\mathrm{a}_{\mathrm{w}}$ and $\mathrm{pH}$ are two the most important parameters. Free water that is available to molds, yeasts, and bacteria is responsible for their growth and even toxin production. Or it may participate in chemical/biochemical reactions (e.g. Maillard reactions), which might deteriorate: texture, flavor, color, taste, nutritional value of a product, and its stability $\rightarrow$ shelf-life time $[4,11,22,33]$.

Water activity $\left(a_{\mathrm{w}}\right)$ has its most useful application in predicting the growth of bacteria, yeasts and moulds. For a food to have a useful shelf life without relying on refrigerated storage, it is necessary to control either its acidity level $(\mathrm{pH})$ or the level of water activity $\left(a_{\mathrm{w}}\right)$ or a suitable combination of the two. This can effectively increase the product's stability and make it possible to predict its shelf life under known ambient storage conditions [22, 34, 45].

Strawberries are delicious fruits, with a good smell and taste, nice appearance.

Strawberries are one of the most important seasonal fruit crops. Most of its production is destined for the fresh market, but because of the short shelf life and seasonal nature of this fruit, part of its production is processed. In this way, it is used as a food ingredient in yogurts, pies, milk shakes, jams, ice creams, etc. because of its interesting sensory attributes. The types of strawberry processing most commonly used to increase product shelf life are freezing, partial or total dehydration and other combined methods. In these cases, the processed fruit undergoes changes in sensory attributes such as texture, color [5, 25, 48] and changes in the profile of volatile compounds [9, 45], making the product different from nontreated products. Other quality attributes, such as product taste or flavor related to fruit composition on major sugars and acidity, may also be altered during such processes [25-27, 53].

Strawberries are perishable and under the action of peroxidase enzymes that contribute to the appearance of brown compounds and the loss of smell, they support permanent changes of phenol substances (their oxidation) [40, 41]. During storage and processing, the content of these substances is reduced according to their involvement in the process of oxido - reduction. Their evolution depends on several factors, as: the chemical composition of the fruits, parameters of the technological process, storage conditions, etc. [38, 41 and 47]. Different approaches have been explored for obtaining shelf-stability and freshness in fruit products. Commercial, minimally processed fruits are fresh (with high moisture), and are prepared for convenient consumption and distribution to the consumer in a fresh state. Minimum processing includes minimum preparation procedures like washing, peeling and/or cutting, packing etc., after which the fruit product is usually placed in refrigerated storage where its stability varies depending on the type of product, processing, and storage conditions.

As a preservation method, freezing combines low temperature and a water activity $\left(\mathrm{a}_{\mathrm{w}}\right)$ reduction associated with the cry concentration of the fruit liquid phase during ice crystal formation. However, because of the highly freezable water content of strawberries, freezing implies important cellular damage and losses in product quality [23]. Water content reduction by dehydration treatments applied before freezing (dehydrofreezing) have been reported as a tool in fruit cryopreservation, mainly because of the reduction of freezable water content $[5,26]$.

In this sense, osmotic dehydration (OD) or air drying (AD) and combined treatments (OD-AD) can be used to reduce ice crystal injuries during frozen storage. Dehydration treatments have been used to obtain strawberry products in the form of ingredients $[11,25]$. These treatments affect the cells of the plant tissue as a result of ruptures in cellular 
bonds and induced deformations (shrinkage/swelling) both in cells and intercellular spaces taking place throughout the drying process. During AD treatment, elimination of water involves phase changes and so, although low temperatures are used during the process, a loss of cell functionality may occur and consequently, considerable changes in sensory and nutritional quality [44].

OD of fruit into an osmotic solution implies an opposite flux of different components: water and some natural soluble substances such as sugars, vitamins, pigments, organicacids, mineral salts, etc. [10] flow out from the fruits the osmotic solution, and in the opposite direction, soluble solutes may be transferred from the solution to the fruit, which may change product taste and acceptability. The penetration of sugar into the fruit is quite a slow process, particularly if high fruit particle integrity is desired in the final product [53]. This method has received considerable attention because of the low energy requirements and fruit quality improvement $[13,14]$. As high temperatures are not normally used in OD processes, and no water phase changes occur, changes in sensory attributes, such as color, aroma, flavor and texture are minimized $[14,30]$.

Strawberry is an excellent source of food ingredients, although compositional changes might occur in improperly controlled processing, affecting product quality. In this sense, OD has been recommended to improve fruit quality in fruits sensitive to AD such as kiwi fruits and strawberries [48]. The operation has been used as an initial step in other processes such as $\mathrm{AD}$ [25] and freezing [5]. However, when partial dehydration of the product is used to obtain slightly processed fruits, a section of the tissue remains alive so that cellular respiration still occurs depending on the dehydration level [37]. Osmotic stress causes physiological and biochemical changes that will lead to modifications in the fruit composition, such as changes in sugars, acids or reserve substances $[3,7]$.

Acellular biochemical response to the osmotic stress has also been observed, resulting in the accumulation of osmolites (compatible solutes) in the cytoplasm that is induced by enzyme action [9].

In this work, the influence of OD (osmotic dehydration of sugar) applied to partially reduce moisture content and $\mathrm{a}_{\mathrm{w}}$ on major sugars and strawberry acidity was analyzed. Likewise, the effect due to subsequent sample freezing and frozen storage was also studied.

\section{Materials and methods}

Chemicals

Folin-Ciocalteu phenol reagent, gallic acid monohydrate, glacial acetic acid, L-ascorbic acid, sodium carbonate was obtained from EM Science, alcohol, hydrochloric acid, sucrose.

\section{Raw material}

Strawberries (var. Victoria) were purchased in a local market in Chisinau (Republic of Moldova). Eight, different batches were used in the study, two for each treatment subsequently described. Strawberry samples were frozen and kept at the temperature of minus $18^{\circ} \mathrm{C}$ for 6 months. The study was conducted both for fresh and frozen strawberries. The estimation of content $\mathrm{SH}$, antioxidants and the reducing state of frozen strawberries was carried out in samples stored 0 , 3 to 6 months. The samples studied were calculated theoretically and modification of water activity $\left(\mathrm{a}_{\mathrm{w}}\right)$. It was evaluated the dependency between the reducing state of frozen strawberries on bio antioxidants content and the influence of the technological process on the quality of strawberries.

\section{Sample freezing}

The samples were congealed in "Ghiocel" freezer at the temperature of $-18^{\circ} \mathrm{C}$. Before congelation preventive operations were made: sorting, washing, top water-drying. The samples were packed in polisterol bags or Al/bald with weight $30.0-50.0 \mathrm{~g}$. Before being hermetically closed, the samples were treated with $\mathrm{N}_{2}$ for reducing the $\mathrm{O}_{2}$ strength. For freezing the samples it was performed the following scheme: reception of raw material $\rightarrow$ washing $\rightarrow$ Inspection $\rightarrow$ removing water from the surface (through vibrating and air blowing) $\rightarrow$ weighting the samples $(\mathrm{g}) \rightarrow$ Packaging, polystyrene packages, aluminium foil. Sample mass $30-50 \mathrm{~g} \rightarrow$ Vacuuming and nitrogen treatment (Pressure value $\mathrm{P}$ $=1.5 \mathrm{~atm}$, for 2-3 minutes) $\rightarrow$ Tightening the packages $\rightarrow$ Freezing at $-18^{\circ} \mathrm{C}$, freezer $\rightarrow$ Storage. Depositing the frozen samples $\left(t=-18^{\circ} \mathrm{C}\right.$, for 3 and 6 months). Nitrogen $\left(\mathrm{N}_{2}\right)$ was used to remove the air from the package, in order to have anaerobic conditions (prevents aerobic spoilage and oxidative degradation of bioantioxidants).

\section{Osmotic treatments}

In some lots, strawberries were packed whole, in other once were congealed whole strawberries or with sugar syrup (syrup strength $39 \%$, syrup: fruits ratio $-1: 3$ ).

\section{Thawing of samples}

Rapid thawing (temperature of $98^{\circ} \mathrm{C}$, for $1-2$ minutes), for the samples in which was determined the content ascorbic acid, polyphenols and anthocyanins. Slow thowning (room temperature, for 30 minutes) for the samples in which was investigated the loss of juice during thawing. In fresh samples and in the congealed one, was estimated the antioxidant capacity, acid ascorbic through method potentiometric; total pholyphenol content through Folin-Ciocalteu 
method; total anthocyanins content through physical-chemical method [39] and property of redox state, expressed with K-index, mg AA/ g HS [46].

\section{Tested indicators}

There were determined the following indicators in the samples: content of soluble substances, the active acidity, $\mathrm{pH}$, the maturity and the content of bio antioxidants: ascorbic acid by potentiometric method, total polyphenols by FolinCiocalteau method, and total anthocyanins by the standard physicochemical method. Also, it was assessed the oxidoreducing state of strawberries by potentiometric method, expressed by the oxido-reducing index (K) [46, 47]. Optical density of samples was evaluated at spectophotometer DR-5000, at a wavelenght of 190-1100 nm.

\subsection{Combining control of water activity with other preservation techniques}

The most important techniques commonly used in food preservation act by inhibiting the growth of microorganisms rather than by inactivating them [12]. Among the inhibitory techniques are: Water activity reduction (curing, conserving, drying, evaporation); Temperature (high or low); Acidity or $\mathrm{pH}$ reduction by addition of inorganic and organic acids; Redox potential (Eh), preservatives (e.g., nitrite, sorbets, and sulphites); Competitive microorganisms (e.g., lactic acid bacteria); Modified atmosphere packaging (vacuum, nitrogen, carbon dioxide, oxygen). As stated by Leistner [21, 22] it soon became apparent that in most foods for which $\mathrm{a}_{\mathrm{w}}$ is important for quality and stability, other factors, referred to by Leistner as "Hurdles", contribute to the desired product, and the interest taken initially in $\mathrm{a}_{\mathrm{w}}$ for food manufacturers was extended to other factors (e.g., Eh, pH, temperature, incorporation of additives, etc.). The goal was to obtain stable products based on an intelligent combination of factors by combination preservation technology or hurdle technology $[2,27]$.

This paper presents the influence of freezing and osmotic treatment (use sucrose solution) on the quality of frozen strawberries.

\subsection{Water activity $\left(\mathbf{a}_{w}\right)$ concept}

Water activity (aw) is defined as the ratio of the equilibrium water vapour pressure of a foodstuff (pw, $\mathrm{kPa}$ ) to the saturated vapour pressure $\left(\mathrm{p}_{\mathrm{wo}}, \mathrm{kPa}\right)$ at the same temperature. It is an important concept in the food industry since it is related to microbiological stability and physico-chemical deterioration reactions. Indeed, water is often the main component of a foodstuff, which also contains carbohydrates, proteins, fats and mineral salts. At particular conditions of temperature and moisture, the interactions between these constituents can cause browning and lipid oxidation, among other reactions, and can provide the appropriate conditions for microbiological growth [17].

Sorption isotherms, which describe water activity at a given temperature at different moisture contents, are therefore of special interest in the design of food preservation processes such as drying, freeze-drying, mixing, packaging, storage, etc., since they are required for the prediction of food stability, shelf life, and glass transitions, for estimating drying times, etc. The sorption behavior of various types of foods and the influence of temperature on equilibrium moisture content have been studied and modelled extensively during the past 50 years [31,32, and 48]. The numerous mathematical expressions reported in the literature may be classified as theoretical, semi-empirical, or empirical models [17].

Each of these models had relative success in reproducing equilibrium moisture content, depending on the water activity range or the type of foodstuff. Some of the better known correlations of water activity as a function of moisture content and temperature are the modification of the correlation [17]. However, none of these are applicable to both high and low moisture products. A very popular general correlation, which is recommended by the European project COST90 on physical properties of foods [17], is the Guggenheim-Anderson-de Boer (GAB) equation. Other semi-empirical correlations based on thermodynamic considerations are those of [17, 34].

\subsection{Prediction of water activity in practical applications}

Water activity $\left(\mathrm{a}_{\mathrm{w}}\right)$ can be influenced in at least three ways during the preparation of dried, intermediate and high moisture foods $[6,21-25,48]$ :

1. Water can be removed by a dehydration, evaporation or concentration process.

2. Additional solute can be added. The impregnation of solute can be preformed by moist infusion or dry infusion. Moist infusion consists in soaking the food pieces in a water-solute solution of lower $\mathrm{a}_{\mathrm{w}}$ while dry infusion involves direct mixing of food pieces and solutes in required proportions. When water-rich solid products, such as fruit, are subjected to moist or dry infusion, three flows arise: a water outflow, from product to the environment; a solute flow, from the environment to product, and an outflow of the product's own solutes.

This process is called "osmotic dehydration" and allows the infusion of not only the solute used to control $\mathrm{a}_{\mathrm{w}}$ but also the desired quantities of antimicrobial and ant browning agents or any solute for improving sensory and nutritional quality. By controlling these above complex exchanges it is possible to conceive different combinations of water loss and solid gain, from a simple dewatering process (with substantial water removal and only marginal sugar pickup) to a 
candying or salting process (in which solute penetration is favored and water removal limited) [48]. For porous foods, moist infusion can be also performed under vacuum, as previously mentioned. The internal gas or liquid occluded in the open pores is exchanged for an external liquid phase (of controlled composition) due to pressure changes.

3. Combining 1.\& 2. When the food pieces are infused with the solutes and additives and then partially dried. The advantages obtained with this combination as compared to only drying are an increase in the stability of the pigments responsible for the colour, an enhancement of the natural flavour, a better texture and a greater loading of the dryer.

Whatever the procedure used to reduce $\mathrm{a}_{\mathrm{w}}$, it is necessary to know the water activity-moisture content relationship in the food. Important contributions have been made in the field of $\mathrm{a}_{\mathrm{w}}$ prediction over the past 50 years and comprehensive analysis of the procedures traditionally employed to calculate $\mathrm{a}_{\mathrm{w}}$ have been performed by Chirife $[6,12]$. In each case, the applicability of various theoretical and empirical equations was analyzed, presenting some descriptive exemples.

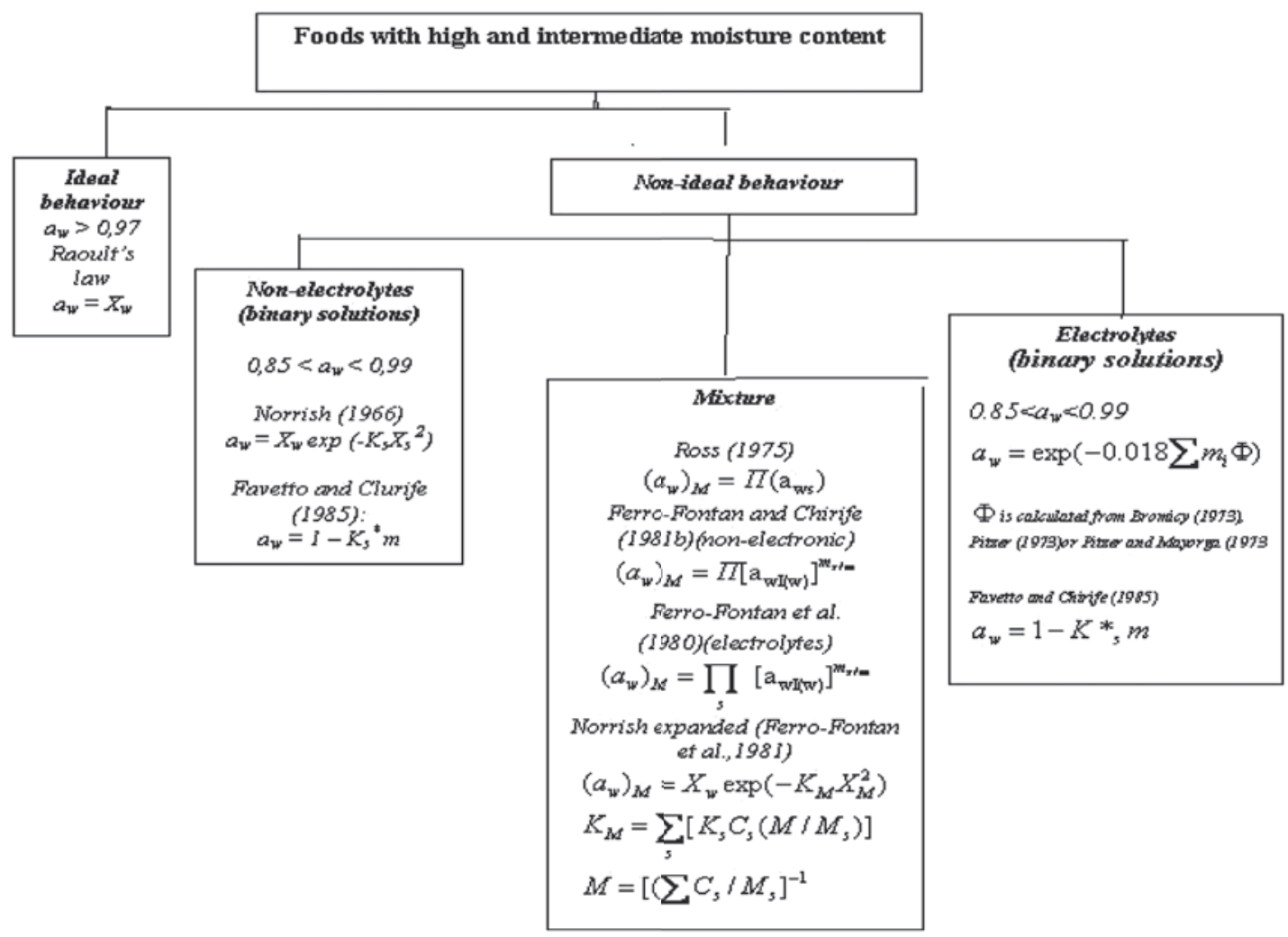

Figure 1. Scheme and selected models for partical prediction of water activity in moist and semi-moist foods

where: $\mathrm{X}_{\mathrm{w}}$ : molar fraction of water; $\mathrm{X}_{\mathrm{s}}$ : molar fraction of solute; $\mathrm{K}_{\mathrm{s}}$ : Norrish 'content for a non-electrolyte $\mathrm{s} ; \mathrm{K}_{\mathrm{s}}^{*}$ : constant for each solute (electrolyte or non-electrolyte); $\mathrm{m}$ : molality; $\mathrm{m}_{\mathrm{i}}=v \mathrm{~m}$, here $v$ is the number of ionic species per mol the solute $i$ : $\Phi$ :osmotic coefficient; $\left(\mathrm{a}_{\mathrm{w}}\right)_{\mathrm{M}}$ : water activity of a complex solution; $\left(\mathrm{a}_{\mathrm{ws}}\right)$ : water activity of each $s$ component when measured at the same molality as in the compex solution; $\mathrm{m}_{\mathrm{s}}$ : molality of the $s$ component in the mixture; $\mathrm{m}_{\mathrm{s}(\mathrm{I})}$ : total molality (dissociated) of the solute that would produce an ionic force equal to the one of the mixture, $a_{w s(I)}$ : water activity of solute $s$ in a binary solution at a molality $\mathrm{m}_{\mathrm{s}(\mathrm{I})} ; \mathrm{C}_{\mathrm{s}}$ : weight of solute $\mathrm{s} /$ weight of total solids; $\mathrm{M}_{\mathrm{s}}$ molecular weight of solute $s$.

A number of equations, based on the thermodynamic properties of binary and multicomponent electrolyte and non-electrolyte solutions, have been studied theoretically and experimentally for calculating or predicting the $\mathrm{a}_{\mathrm{w}}$ of these foods. Figure 1 summarizes several of theoretical and empirical models suggested for the calculation of $\mathrm{a}_{\mathrm{w}}$ in semi-moist and moist food $[6,12,16]$.

In low-moisture foods, adsorption of water in surfaces is responsible for $a_{w}$ reduction [6, I5]. Although the physical chemistry of surfaces has provided the food scientists with a large number of the theoretical equations, the relationship of water sorption $-\mathrm{a}_{\mathrm{w}}$ cannot be predicted but must be experimentally determined due to many reasons. As food sorbs water, it can undergo changes of constitution, dimensions and other properties and sugars contained in the food may experience phase transformations. Although the theoretical assumptions are incorrect for heterogeneous food surface interactions, for practical purposes this equation has been found very useful in determining the optimum moisture content (i.e., that corresond to the monolayer water) for storage chemical stability of dehydrated foods [29]. 
The Guggenheim, Anderson and Boer (GAB) equation [50,54] (applicability range $0<\mathrm{a}_{\mathrm{a}}<0,9$ ), is now recognized as the most versatile sorption model and recommended as such by the European COST 90 Project. This, it was found to be suitable for analysing more then $50 \%$ of fruits, meat and vegetables. It also allows calculation of the monolayer water (Maroulis et al., 1988) [1]. The thermodynamic description of these osmotic solutions has been the object of intense research all along the last century, particularly those involving sugars and/or salts. Excellent review soft such efforts have been written [29-35]. Most thermodynamic models used to describe vapors-liquid equilibrium of osmotic solutions are based on relations involving Gibbs free energy of the system. Of particular interest is the excess Gibbs energy $\left(\mathrm{G}^{\mathrm{E}}\right)$ and for each of the components the partial molar excess Gibbs energy $\left(\mathrm{g}_{\mathrm{i}}^{\mathrm{E}}\right)$, both allowing a convenient way to quantify the deviations from ideal behavior $[1,19,44]$.

From $\mathrm{G}^{\mathrm{E}}$, a large number of physical parameters may be calculated such as water and solute activities, partial equilibrium properties (solubility, relative volatility, etc.) and others. The activity of water in aqueous solutions is defined as [44]:

$$
a_{a}(T, P, x)=\gamma_{W}(T, P, x)=\frac{f_{w}(T, P, x)}{f_{w}^{o}(T, P, x)}
$$

where:

$\mathrm{a}_{\mathrm{w}}$ is the water activity, $\mathrm{x}_{\mathrm{w}}$ is the mole fraction of water,

$\gamma_{w}$ is the activity coefficient for water,

$f_{w}, f_{w}^{o}$ are the water fugacity in the system and at reference conditions, respectively.

It is usually assumed that under normal working conditions of ambient temperature and atmospheric pressure, gas phases behave ideally and so the ratio fugacity can be taken as the ratio of partial pressures [44]:

$$
\frac{f_{w}}{f_{w}^{o}}=\frac{p_{w}}{p_{w}^{o}}
$$

Where: respectively.

$\boldsymbol{p}_{w}$ and $\boldsymbol{p}^{o}{ }_{w}$ are the vapor pressures of water in the system and of pure liquid water at the same temperature,

Under this assumption, from eq.(1):

$$
a_{w}=\frac{p_{w}}{p_{w}^{0}}=\frac{R H}{100}
$$

Where:

$\mathrm{RH}$ is the percent relative humidity of the air layer in equilibrium with the sample. $[44,54]$

The activity coefficient $\gamma_{w}$ may be calculated directly from the partial molar excess Gibbs energy of water, $g_{w}^{E}$

$$
g_{w}^{E}=R T \ln \gamma_{w},
$$

And for the total molar excess Gibbs energy, $\mathrm{g}^{\mathrm{E}:}$

$$
g^{E}=R T \sum_{i} x_{x} \ln \gamma_{i}
$$

For an ideal solution all the activity coefficients, $\gamma_{i}(T, P, x)$, are equal to one, corresponding to an excess, Gibbs energy equal to zero.

Dependence of activity coefficient on temperature may be expressed in terms of the excess partial molar enthalpy or the partial molar excess heat of mixing as [52]: 


$$
\left[\frac{d \ln \gamma_{i}}{d T}\right]_{p}=\frac{h_{i}^{E}}{R T^{2}},
$$

After integration between two different temperatures, a form of the well-known Clausius-Clapeyron [49] equation is obtained:

$$
\operatorname{In} \frac{\left(a_{w}\right)_{T 1}}{\left(a_{w}\right)_{T 2}}=\frac{h_{W}^{E}}{R}\left(\frac{1}{T_{1}}-\frac{1}{T_{2}}\right)^{\prime}
$$

When $h^{E}$ is constant along the path $\mathrm{T}_{1}$ to $\mathrm{T}_{2}$.

In spite of this elegant way of expressing temperature dependence, some empirical equations have been proposed $[44,52]$, often involving a considerable number system specific parameters. Analysis of the comparative performance of different predictive models for water activity has revealed that good estimations may be obtained, not only from empirical equations with parameters fitted to experimental data but also from theoretical models derived from expressions of the excess Gibbs free energy and from equations of state [42] It is somehow surprising how good the predictions made from group contribution models are. These truly predictive models use group interaction parameters not necessarily calculated from data involving the components of interest. Due to these capabilities, further effort and testing should be devoted to this group of techniques [52].

For practical applications of osmotic treatments, the most widely used equations for prediction of water activity in binary are the ones of Norrish [28] and Ross [36]. Parameters calculated by Chirife bet al., 1980 should be preferred for use with Norris equation. For solution containing electrolytes [40] equation are recommended. For water activity of multi-component mixtures good results are obtained using Ross [36] equation with any of the already mentioned single solute models. Recently Roa and Tapia [35] have proposed a simple equation, based on the first-order sum of molalities, with a reasonable predictive accuracy.

The use of UNIFAC and ASOG models as well as equations of state, although constituting a good and accurate tool to estimate the activity coefficients of non-electrolyte and electrolyte mixture, are not yet widely used in everyday practical application of osmotic treatments $[55,44]$.

\subsection{Mathematical modeling}

The GAB and Ratti et al. [1, 34] models of sorption equilibrium were tested against the experimental data. The $\mathrm{GAB}$ equation is usually presented in the form [17]:

$$
\frac{X}{X_{m}}=\frac{C K a_{w}}{\left(1-K a_{w}\right)\left(1-K a_{w}+C K a_{w}\right)}
$$

Where:

$\mathrm{X}=$ water content (dry basis, $\mathrm{kg}$ water/kg dry solids),

$\mathrm{a}_{\mathrm{w}}=$ water activity,

$\mathrm{Xm}=$ monolayer water content, a constant of the GAB equation, and

$\mathrm{C}, \mathrm{K}=$ constants related to temperature (defined by Eqs. 9 and 10).

$$
\begin{gathered}
C=C_{o} \exp \left(\frac{\Delta H_{1}}{R T}\right) \\
K=K_{o} \exp \left(\frac{\Delta H_{2}}{R T}\right)
\end{gathered}
$$

Where $\mathrm{C}_{\mathrm{o}}, \mathrm{K}_{\mathrm{o}}, \Delta \mathrm{H}_{1}, \Delta \mathrm{H}_{2}=$ fitting constants, which can be obtained through non-linear regression.

The mathematical model developed by Ratti et al. [34] is an equilibrium equation based on thermodynamic concepts [17]:

$$
\ln a_{w}=M(X)+N(X) \ln p_{w o}
$$


Where: the effect of temperature is included in the vapour pressure of pure water, $p_{w 0}$.

For high moisture foods, such as fruits, mushrooms, and vegetables, the parameters $\mathrm{M}(\mathrm{X})$ and $\mathrm{N}(\mathrm{X})$ are functions of water content, expressed as:

$$
\begin{gathered}
M(X)=-k_{1} X^{k_{2}} \\
N(X)=k_{3} \exp \left(-k_{4} X\right) X^{k_{3}}
\end{gathered}
$$

The parameters $\mathrm{k}_{1}, \mathrm{k}_{2}, \mathrm{k}_{3}, \mathrm{k}_{4}$, and $\mathrm{k}_{5}$ of Eqs. 5 and 6 can be obtained from experimental data through non-linear regression.

When fitting the models to the experimental data, constants were obtained using the Levenberg-Marquardt procedure for non-linear least squares problems as implemented Sigma Plot (1992) in [17] In this method, the stopping criterion that determines when the least squares minimum has been attained is based on the tolerance, which is set to 0.0001 by default. The parameter Norm, used by the method, represents the closeness of the most recent iteration. Numerically, it is the square root of the sum of the residuals [17, 44]:

$$
\text { Norm }=\sqrt{\sum_{i=1}^{n}\left(y p_{i}-y_{i}\right)^{2}}
$$

Where: $y_{p i}, y_{i}=$ predicted and experimental values, respectively.

The comparison to find the best correlation to represent the experimental data was based on the percentage standard error, E, of experimental versus predicted water activity [34]:

$$
E=100 \sqrt{\sum_{i=1}^{n}\left(y p_{i}-y_{i}\right)^{2} / n}
$$

Where: $\mathrm{n}=$ number of observations.

Strawberries are one of the most important seasonal fruit crops. Most of its production is destined for the fresh market, but because of the short shelf life and seasonal nature of this fruit, part of its production is processed. In this way, it is used as a food ingredient in yogurts, pies, milk shakes, jams, ice creams, etc. because of its interesting sensory attributes. The types of strawberry processing most commonly used to increase product shelf life are freezing, partial or total dehydration and other combined methods. In these cases, the processed fruit undergoes changes in sensory attributes such as texture, color [5, 26, 47] and changes in the profile of volatile compounds [7, 45], making the product different from nontreated products. Other quality attributes, such as product taste or flavor related to fruit composition on major sugars and acidity, may also be altered during such processes [25, 53].

As a preservation method, freezing combines low temperature and a water activity $\left(\mathrm{a}_{\mathrm{w}}\right)$ reduction associated with the cry concentration of the fruit liquid phase during ice crystal formation. However, because of the highly freezable water content of strawberries, freezing implies important cellular damage and losses in product quality [25, 26]. Water content reduction by dehydration treatments applied before freezing (dehydrofreezing) have been reported as a tool in fruit cryopreservation, mainly because of the reduction of freezable water content $[5,26]$. As a preservation method, freezing combines low temperature and a water activity (Aw) reduction associated with the cry concentration of the fruit liquid phase during ice crystal formation. However, because of the highly freezable water content of strawberries, freezing implies important cellular damage and losses in product quality [26]. Water content reduction by dehydration treatments applied before freezing (dehydrofreezing) have been reported as a tool in fruit cryopreservation, mainly because of the reduction of freezable water content $[5,26]$.

\section{Results and Discussion}

The objective of the present work was to evaluate storage stability of frozen strawberry processed by a previous osmotic dehydration at atmospheric pressure $(760 \mathrm{mmHg})$. The stability was assessed monthly by means of physico- 
chemical and sensorial methods, during 6 months of storage at congelend temperature. Table 1 shows Aw and $\mathrm{pH}$ values, concentrations of water, soluble solids, sucrose and citric acid of each strawberry fresh, before and after dehydration treatment (osmotic dehydration OD).

Table 1

Physico-chemical characteristics of strawberry

\begin{tabular}{|c|c|c|c|c|c|c|}
\hline Sample & HS, \% & $\mathrm{W}, \%$ & $\mathrm{pH}$ & $\begin{array}{c}\text { Total acidity } \\
(\mathrm{AC}), \%\end{array}$ & $\begin{array}{c}\text { Total } \\
\text { Sucrose }(\mathrm{S}), \\
\%\end{array}$ & $\begin{array}{c}\mathrm{a}_{\mathrm{w}, \mathrm{m}} \\
\text { calculated } \\
\text { theoretically }\end{array}$ \\
\hline Fresh fruits & $7.5 \pm 0.5$ & $92,4 \pm 0,6$ & $3.5 \pm 0.05$ & $0.85 \pm 0,06$ & $6.4 \pm 0,6$ & $0.990 \pm 0.001$ \\
\hline OD & $8.3 \pm 0,3$ & $90.2 \pm 0,5$ & $3.75 \pm 0.08$ & $0.82 \pm 0.05$ & $7.0 \pm 0,3$ & $0.982 \pm 0.002$ \\
\hline
\end{tabular}

OD, osmotic dehydration

Changes the physical and chemical indicators in frozen fruit

\begin{tabular}{|c|c|c|c|c|c|}
\hline Sample & $\begin{array}{l}\text { Maintenance time } \\
\text { in frozen decrease, } \\
\text { months }\end{array}$ & $\mathrm{W}, \%$ & $\mathrm{SH}, \%$ & $\mathrm{~S}, \%$ & $\mathrm{AC}, \%$ \\
\hline \multirow{3}{*}{ FS } & $\mathrm{BF}$ & $92.4 \pm 0,6$ & $7.5 \pm 0.5$ & $6.4 \pm 0,6$ & $0.85 \pm 0,06$ \\
\hline & 3 months & $92.2 \pm 0.3$ & $7.6 \pm 0.3$ & $6.8 \pm 0.5$ & $0,86 \pm 0.04$ \\
\hline & 6 months & $92.1 \pm 0.5$ & $7.8 \pm 0.6$ & $6,7 \pm 0.5$ & $0.88 \pm 0.03$ \\
\hline \multirow{3}{*}{ OD } & $\mathrm{BF}$ & $90.2 \pm 0,5$ & $8.3 \pm 0,3$ & $7.0 \pm 0,3$ & $0.82 \pm 0.05$ \\
\hline & 3 months & 90.2 & $8.5 \pm 0.0$ & $6.8 \pm 0.4$ & $0,82 \pm 0.04$ \\
\hline & 6 months & 90.1 & $8.3 \pm 0.1$ & $6.9 \pm 0.5$ & $0.81 \pm 0,04$ \\
\hline
\end{tabular}

Sensorial analyze of frozen strawberry appearance showed that the fruit color remained almost the same compared to the fresh fruits. We observed just a weak appearance of brown color. Analyzing the contents of L-hidroascorbic acid, pholyphenols and whole anthocyanins it was observed a diminution of these indexes on depositing way. Medium values are presented in Table 2. Higher shown index diminution was different: depending by the staple primary quality, staple procession previous freezing, keeping term and pack quality. The antioxidants activity consists the biological value of the fruits. These indicators are directly proportional $[46,47]$. The biological value of the product is higher with the increasing of the reducing activity. The basic indexes that characterize the reducing activity of the antioxidants are oxido-reducing condition [47]. As the chemical composition of strawberries, including content and antioxidant activity was very variable, the experimental data were analyzed by statistical methods, using the probability theory $[40,42]$.

Table 3

The capacity modification of antioxidants in congealed strawberry

\begin{tabular}{|c|c|c|c|c|}
\hline \multirow{2}{*}{$\begin{array}{c}\text { Maintenance time, } \\
\text { months }\end{array}$} & \multicolumn{3}{|c|}{ Antioxidants content, mg/100g } & \multicolumn{2}{c|}{$\begin{array}{c}\text { Redox state } \\
\text { decrease } \\
\text { K, mg AA/gHS }\end{array}$} \\
\cline { 2 - 4 } & L-hidro-ascorbic acid & Total polyphenols & Total anthocyanins & \\
\hline Primary & $21.7 \pm 0.39$ & $157.0 \pm 1.93$ & $35.2 \pm 0.37$ & $15.0 \pm 0.38$ \\
\hline
\end{tabular}




\begin{tabular}{|l|c|c|c|c|}
\hline After 3 months & $19.6 \pm 0.49$ & $130.8 \pm 1.68$ & $30.6 \pm 0.36$ & $8.9 \pm 0.43$ \\
\hline After 6 months & $19.2 \pm 0.54$ & $96.5 \pm 1.60$ & $28.9 \pm 0.42$ & $3.5 \pm 0.45$ \\
\hline \multicolumn{4}{|c|}{ Entier strawberry with sugar } \\
\hline Primary & $21.7 \pm 0.39$ & $157.0 \pm 1.93$ & $35.2 \pm 0.37$ & $15.0 \pm 0.38$ \\
\hline After 3 months & $19.8 \pm 0.30$ & $145.5 \pm 0.85$ & $34.6 \pm 0.25$ & $12.5 \pm 0.30$ \\
\hline After 6 months & $19.2 \pm 0.28$ & $115.3 \pm 1.05$ & $32.5 \pm 0.33$ & $7.3 \pm 0.25$ \\
\hline
\end{tabular}

It was found that there is a slow degradation of antioxidants in the frozen strawberries in the first three months of storage. At a longer storage - the oxidative degradation of antioxidants is faster. The study reveals a decrease in: polyphenol content within $157.0 \pm 1.93 \ldots .96 .5 \pm 1.60 \mathrm{mg} / 100 \mathrm{~g}$; anthocyanin content within $35.2 \pm 0.37 \ldots 28.9 \pm 0.42$ $\mathrm{mg} / 100 \mathrm{~g}$, and L-Hydroascorbic acid content $21.7 \pm 0.39 \ldots 19.2 \pm 0.54 \mathrm{mg} / 100 \mathrm{~g}$ (full strawberry's without sugar). The content of antioxidants in congealed fruits, before and after dehydration treatment (osmotic dehydration OD) is less reduced (Table 3).

Table 4

Rate value antioxidants contents in congealed strawberry diminutions

\begin{tabular}{|c|c|c|c|c|}
\hline \multirow{2}{*}{$\begin{array}{l}\text { Maintenance } \\
\text { time in frozen } \\
\text { decrease, } \\
\text { months }\end{array}$} & \multicolumn{4}{|c|}{ Medium value of antioxidants content diminution, $\%$} \\
\hline & L-hidroascorbic acid & Total polyphenols & Total anthocyanins & $\begin{array}{c}\text { Redox state decreasing } \\
\mathrm{K}, \mathrm{mg} \text { AA/gHS }\end{array}$ \\
\hline \multicolumn{5}{|c|}{ Entier strawberry without sugar } \\
\hline 3 & $9.68 \pm 0.44$ & $16.69 \pm 1.81$ & $13.8 \pm 0.37$ & $40.67 \pm 0.41$ \\
\hline 6 & $11.52 \pm 0.47$ & $38.54 \pm 1.76$ & $17.9 \pm 0.40$ & $76.87 \pm 0.42$ \\
\hline \multicolumn{5}{|c|}{ Entier strawberry with sugar } \\
\hline 3 & $8.76 \pm 0.35$ & $7.32 \pm 1.39$ & $1.70 \pm 0.31$ & $16.67 \pm 0.34$ \\
\hline 6 & $11.52 \pm 0.34$ & $26.56 \pm 1.49$ & $7.6 \pm 0.55$ & $51.33 \pm 0.32$ \\
\hline
\end{tabular}

Therefore, it was found that during the storage of frozen strawberries there are changes in the content of antioxidants and their oxido-reducing. Reduction of these features is a function of shelf life and of freezing temperature. Contents diminution in polyphenols after 6 months at frozen strawberry without sugar was medium estimated at $38.54 \pm 1.76 \%$, contents diminutions in anthocyanins were medium estimated at $17.9 \pm 0.40 \%$, but contents diminution in ascorbic acid were estimated at $11.52 \pm 0.47$ (Table 4). This study showed the lower reduction of all investigated parameters within processing strawberries OD: contents in anthocyanins were medium of 7.65 , being of about 2.36 times less. Probably this is due to the osmosis.

It was found that in congealed and stored strawberries at the temperature of $-18^{\circ} \mathrm{C}$ there is a slow antioxidant degradation in first months. At a longer depositing period $\left(10\right.$ months, $\left.\mathrm{t}=-18^{\circ} \mathrm{C}\right)$ biologically active substances are oxidative degraded at an accelerated rate. The degree of degradations occurs in the following sequence: polyphenols, ascorbic acid, anthocyanins, and the content of biologically active substances in dependency of raw material, conditions of storage, processing, freezing and storage [37-39]. Probably through the water contents in unfrozen decrease we can explain a very big diminution of polyphenols, ascorbic acid and anthocyanins in investigation samples. The activity and enzymatic reaction speed almost touches the maximal values of water stratums in frozen strawberry. Probably this phenomenon leads at modification the chemical compounds, plus antioxidants and redox state decrease in food environment.

In the frozen products the enzymatic reactions are slower, but not completely blocked. In general, the enzyme activity in frozen strawberries is related to the presence of unfrozen water. At a temperature of minus $18^{\circ} \mathrm{C}$ the water content in frozen strawberries is about $89 \%$ of total water content. The unfrozen water will be $11 \%$. At a temperature of minus $30^{\circ} \mathrm{C}$ the frozen water content will be $91 \%$ of the total water content and $9 \%$ of unfrozen water [8]. 
One of the majore changes that arise in foods during storage is constituted by Maillard reactions, in which gives rise to a series of final products which contribute particularly to modifying the taste, other chemical changes that can take place are the degradation of vitamin $\mathrm{C}$ and other nutrients, state that both carotenoids such as vitamin $\mathrm{C}$ may gradually degrade during storage, the stability of temperature being affected [26]. During storage of concentrated apple juice, [3] we can observe that although the amino acids involved in the Maillard reactions, reaction rates being very different. Thus, for example, glutamic acid, asparagine and aspartic acid, were affected by this process. The biochemical changes that occur in food are also the origin of other variations in quality parameters, eg., flavor, aroma and color [18].

Analyzing the color changes in grapefruit juice during storage, [20] found a clear negative linear relationship with other parameters, such as sugars and ascorbic acid, so that as the browning increases, the acid concentrations ascorbic acid and sugars decrease, also saw a clear relationship with the accumulation of furfural and 5-hydroxymethyl furfural. In this regard, [33] consider that the analysis of the variation in the content of 5-hydroxymethyl furfural is a good indicator of the occurence of non-enzymatic browning processes.

It was proved that depreciation of the final products exterior aspect and the appearance of a brown colour is due to antocyanins and polyphenols degradation and formation of brown composites identified in the spectral UV area of $220 \ldots 270 \mathrm{~nm}$. Spectral analysis of strawberries samples demonstrated that appearance impairment of strawberries and occurrence of brown color is determined by degradation of anthocyanins, polyphenols and creation of brown compounds. In figure 2 are presented Optic density spectrums for frozen strawberries samples after six months of depositing.

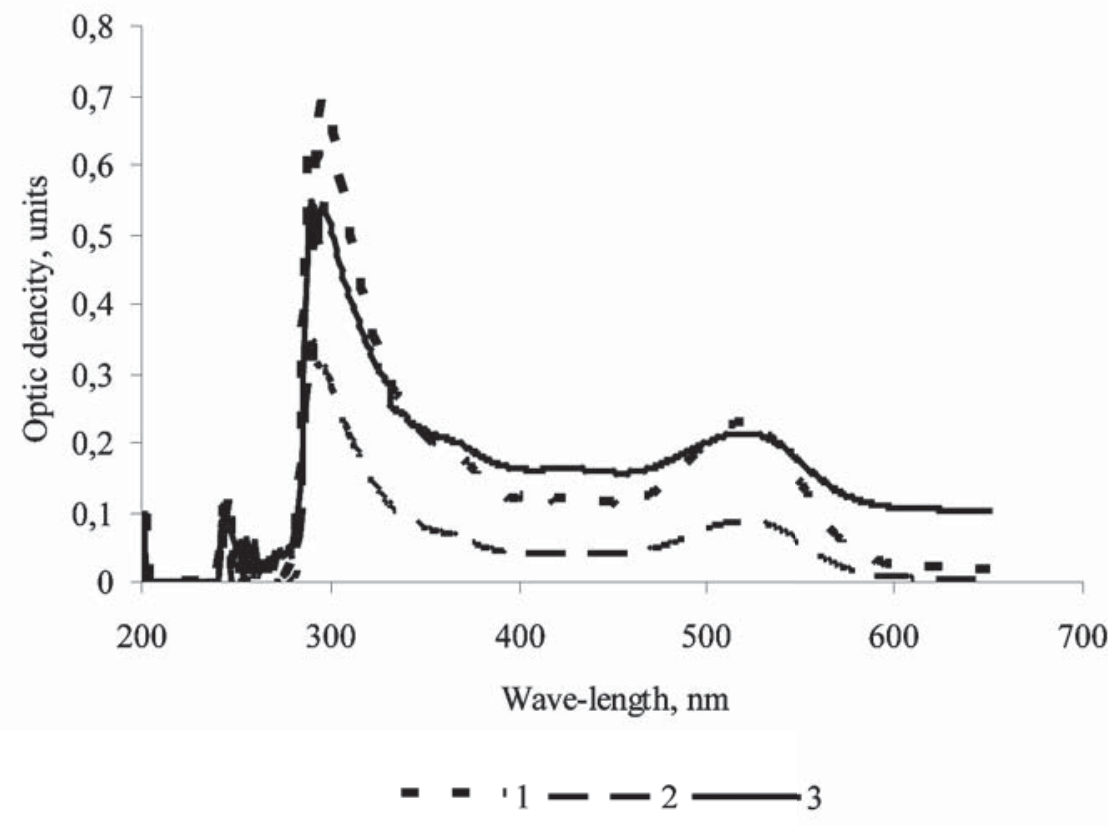

Figure 2. Optic density spectrums for frozen strawberries after six months of depositing

In freezing case when using sugar, we can explain the sugar action, by the reduced content of water in fruits. Analyzing examined samples we see optic density spectrum: frozen strawberries without sugar (1), frozen strawberries with sugar syrup (2), and frozen strawberries with sugar (3) after 6 months of depositing at the temperature $-18^{\circ} \mathrm{C}$ we can see the sugar influence on strawberry color stability. We observe in the case of samples 1 and 2 that optic density extension on wave-light interval $\lambda=500-540 \mathrm{~nm}$, associated with anthocyanins presents in samples, it was more relevant compared with 3-rd sample. $\mathrm{D}_{\lambda .519}=0.228$-for frozen strawberries without sugar (1). $\mathrm{D}_{\lambda 519}=0.088$ - for frozen strawberries with sugar syrup (2). $\mathrm{D}_{\lambda 519}=0.214$ - for frozen strawberries with sugar (3).

\section{Conclusions}

The oxido-reducing state of strawberries depends on the content of polyphenols, anthocyanins and ascorbic acid. The oxido-reducing state is strongly influenced by the content of polyphenols.

In frozen strawberries, during storage there are nutritional and sensory properties changes, resulting in loss of quality. Quality can be determined by analyzing the kinetics of the changing of the bio antioxidants activity. 
It was found that the frozen strawberries stored at a temperature of $-18^{\circ} \mathrm{C}$ in the first three months show a slow degradation of the biologically active substances. We discover that in congealed strawberry of keeping at the temperature of $-18^{\circ} \mathrm{C}$ in first months, we see slow antioxidant degradation, but at a longer depositing way we see a higher speed oxidative degradation. Sugar has a significant effect on water activity and stability of the antioxidants in frozen strawberries.

\section{References}

[1]. Andrade, R .D et al. Models of sorption isotherms for food: Uses and limitations. Universidad de Antioquia, Medellin, Columbia, 2011, p. 325 - 334.

[2]. Alzamora, S. M., Preservacion I: alimentos conservados por factores combinados. I. J. M. Aguilera (Ed), Te, as en Tecnologia de Alimentos, Vol. 1 Mexico, 1997, p. 45-89.

[3]. Babsky, N., et al. Influence of storage on the composition of clarified apple juice concentrate. J. Food Sci.51:564567, 1986.

[4]. Burdurlu, H. S. \& Karadeniz, F., Effect of storage on noenzymatic browning of apple juice concentrates. Food Chemistry 80, 2003, 91-97.

[5]. Chiralt, A., et al., Changes in mechanical properties throughout osmotic processes: Cryoprotectant effect. J. Food Eng. 49, 2001, 129-135.

[6]. Chirife, J et al., The prediction of water activity in aqueous solution in connection with intermediate moisture foods: IV. Aw preduction in aqueous non-electrolyte solutions. Journal of Food Technology, 15, 1980, 59-70.

[7]. Dixon, G. M. and Jen, J. J. Changes of sugar and acids of osmovacdried apple scices. J. Food Sci, 42, 1877, 1126-1127.

[8]. Duckworth, K. B. Water relations of foods Academic press, London, 1975, 156-164, 376 p.

[9]. Escriche, I., et al. Influencece of blanching-osmotic dehydration treatments on volatile fraction of strawberries, J, Food Sci, 65, 2000, 1107-1111.

[10]. Garcia-Martinez, E.et al.Caracterissation of reused osmotic solution as ingredient in new product formulatin. Food Res. Int, 35, 2002, 307-313.

[11]. Garrote, R. L. and Bertome, R. A., Osmotic concentration at low temperature of frozen strawberry halves: Effect of glycerol, glucose and sucrose solutions on exudate loss during thawing. Lebensm.Wiss. Technol. 22, 1989, 264-267.

[12]. Gould, W., Drying, raised osmotic pressure and low water activity, in Gould G W. Mechanisms of Action of Food Preservation Procedures, New York, Elsevier Applied Science, 1989 Crapiste, G. \& E. Rotstein, 1986. Prediction of sorptional equilibrium data for starch-containing foodstuffs. Journal ofFood Science 47: 1501-1507.

[13]. Gustavo V. Barborosa -Canovas et al., Water activity in foods: Fundamentals and Applications, IFT Press, Blackwell Publishing Professional, 2121, USA, 2007.

[14]. Hehg, K. et al., Osmotic dehydration of papaya: influence of process variables on the product quality. Sci. Aliment 10, 1990, 831- 848 .

[15]. Iglesias, H.A. and J. Chirife. Prediction of the effect of temperature on water sorption isotherms of food materials, Journal of Food Technology 11: 109-116, 1976.

[16]. Kitic, D., et al., Theoretical Prediction of the Water Activity of Standard Saturated Salt Solutions at Various Temperatures, J. Food Science,V51, Issue4, 1986, p.1037-1041 http://www.fcfar.unesp.br/arquivos/493336. pdf.

[17]. Khalloufi, S., Glasson, J. and Ratti, C., Water activity of freeze dried mushrooms and berries, Department of Food Science and Nutrition Canada G1K 7P4. 2000.

[18]. Konopacka \& Plocharski, Proceedings of the International Conference on Quality in Chains, an Integrated View on Fruit and Vegetable Quality: Wageningen, The Netherlands, Том 604, Выпуск 1, 2003.

[19]. Labuza, T. P. et al. Mathematical models for optimization of flexible film packeging of food for storage. T AAE, $15,1972,150-155$.

[20]. Lee, H. S. \& Nagy S. Quality changes and nonenzymatic browning intermediates in grapefruit juice during storage. Journalof Food Science 53(1): 168-172. 1988.

[21]. Leistner, L. „Combined methods for food preservation, in Shafiur Rahman M, Food Preservation Handbook, New York, Marcel Dekker, Inc.:457-485, 1999.

[22]. Leistner, L. Gould, G.W., Hurdle Technologies, Combination Treatments for Food Stability, Safety and Quality, New York, Kluwer Academic/Plenum Publishers, 2002.

[23]. Maestrelli, A. et al. Dehydrofreezing of sliced srawberries: a combined technique for improving texture. In Engineering \& Food Processing ICEF 7 Vol 2( R. Jowitt, ed) pp.37-40, Sheffield Academic Pewss, Sgeffield, UK. 
[24]. Marc le Maguer, Mass Transfer Modeling in Structured Foods, FOOD Enginering 2000, Food Engineering Seies, 1997 Part IV, 253-269, DOI: 10.1007/978-1-4615-6057-9_14.

[25]. Moraga, G. et al,. Influence of convective and osmotic drying on some color and firmness properties of strawberry. In Proceedings of $12^{\text {th }}$ International Drying symposium, IDS 2000, P.J. A. M. Kerkhof et al. CD Rom, Elsevier Science B.V., Noordwijkerhout, Netherlands.

[26]. Moraga, G., et al.., Compositional changes of strawberry due to gehyfration, cold strorage and freezing-thawing processes, Journal of Food Processing and Preservation 30, 2006. 459 - 474.

[27]. Moreno, J. et al., Effect of blanching/osmotic combined methods on quality and stability of minimally processed strawberries. Food Res. Int, 33, 2000. 609-616.

[28]. Norrish, R. S., An equation for the activity coefficients and equilibrium relative humidities of water in confectionery syrups. Journal of Food Technology, 1(1), 1966, 25-39.

[29]. Panagiotoi, N. M., et al., Mass transfer modelling of the osmotic dehydration of some fruits. Int. J. Food. Sci. Tech. 33, 1998, 267-284.

[30]. Pinnavaia, G., et al. Dehydrofreezing of fruit using direct osmosis as concentration process. Acta Aliment Pol.41, 1988, 51-57.

[31]. Pioter, P. L., Water sorpt ion isotherms and their estimation in food model mechanical mixtures. Journal of Food Engineering 32: 47- 68, 1997a.

[32]. Pioter, P. L., A three parameter equation for food moisture sorption isotherms. Journal of Food Process Engineering 21: 127-144, 1997b.

[33]. Ramirez-Jimenez et al., Evolution on non enzymatic browning during storage. Food Chemistry, 83, 2003, 219225.

[34]. Ratti, C., G. H. Crapiste and E. Rotstein. A new water sorption equilibrium expression for solid foods based on thermodynamic considerations, Journal of Food Science 54:738-742, 1989.

[35]. Roa, V., \& Tapia, M.S., estimating water activity ins ystems containing multiple solutes based on solute properties. Journal of Food Science 63(4), 559-564, 1998.

[36]. Ross, K. D. Estimation of water activity in intermediate moistrure foods, Food technol. 29, 1975, 26-30.

[37]. Sandulachi, E., Determinarea stării oxido-reducătoare a căpşunilor şi zmeurii de conținutul în acid ascorbic, antociane şi polifenoli totali. Meridianul Ingineresc, U.T.M., Chişinău, 3, 2006, 48-52.

[38]. Sandulachi, E., \& Tatarov, P. Determinarea stării reducătoare a căpşunelor congelate de conținutul în acid ascorbic, antociane şi polifenoli totali, 2006, Meridianul Ingineresc, U.T.M., Chişinău, 4, 2006, 93-97.

[39]. Sandulachi, E. \& Macari, A.,. The modification capacity of antioxidants in congealed, International Symposium Euro-Aliment 2007, Galați, România, Editura Academica, 2007, p.86-88.

[40]. Sandulachi, E., Tatarov, P., \& Croitor, D., The estimation of dependency of fresh berries physico-chemical properties on storage and processing conditions, Annals. Food Science and Technology, Valahia, 2010, 13-15.

[41]. Sandulachi, E., Tatarov P. and Croitir, D., The evolution of frozen straberries quality by studying the kinetics change of antioxidants activity, Journal of Food Research, Vol. 1, No. 1, February 2012 Journal of Food Research, Vol1. No1. Copyright $($ C Canadian Center of Science and Education, www.ccsenet.org/jfr p. 225 -238, 2012.

[42]. Sereno A.M. et al. Preduction of water activity of osmotic solution J. of Food Engineering 49, 2001,103-114.

[43]. Snegiryova, I., i dr., Sovremennie metodi issledovania cacestva pisevih productov. Izdatelistvo Econimica, Moscova. 1976.

[44]. Spiess, W.E.L and Beshnilan, D., Osmotic treatments in food processing, Current state and texture needs, in Proceedings of the $11^{\text {th }}$ International Drying Symposium, IDS'98 (C.B. Akritidis et al.), 1998, pp.47-56.

[45]. Talens, P., et al. 2000, Kinetics and equilibrium status in osmotic dehydration of strawberry. In Proceedings of 12 th International Drying Sympotion of strawberry.In Proceedings of 12 th International Drying Symposium, IDS, 2000 (P.J.A.M.M Kerkhof, W.J. Coumans and G.D.Mooiweer) CD-Rom, Elsevier Science B.V., Noordwijkerhout, Nerherlands Tatarov, P., et al., Book of the International SymposiumEuro-aliment, Galati, 2005.pp. 12-15.

[46]. Tatarov, P., et al., Shele-life prediction of plum foods using antioxidant activity indices, Chem. J. Moldova, 3 (2), 2008, 65-69.

[47]. Torreggiani, D., et al., Influence of osmotic dehydration on texture and pectic composition of kiwi fruit slices, In Proceedings of the $11^{\text {th }}$ International Drying Symposium, IDS'(C.B.Akriridis et al.) 1998, pp. 930-937, Ziti Editions, Thessaloniki, Greece.

[48]. The Clausius Clapeyron Equation,http://chemed.chem.purdue.edu/genchem/topicreview/bp/ch14/clausius.php.

[49]. Van den Berg, C., Description of water activity of foods for engineering purposes by means of the GAB model of sorption. In: Engineering and Food Ed B. M. McKenna. London, England: Elsevier Applied Science. 1984.

[50]. Welti-Chanes, J. et al., Technomic Publishing Company, Inc., Lancaster, PA., 2000, pp. 793-797. Vidal, J., 
Izoterm, mathematical model, food processing, drying, diffusivity. Keywir Termodynamics: applications in chemical engineering and the petroleum industry. Editions Technic, Paris, 2003.

[51]. Viberg, U. \& Sjoholm, I. Sucrose inversion during osmotic pre-treatment of strawberries, Lebensm.-wiss, Technol. 31, 1998, 546-551.

[52]. Yunda,Liuetal. Thermodynamicsofconcentratedelectrolytesolutions, ChemicalEngineering Communications, Vol 77, Issue 1, 1989, p. 43-66.

[53]. Zhiming, Yao \& Marc Le Maguer. Mathematical modelling and simulation of mass transfer in osmotic dehydration processes.Journal of Food Engineering,V. 32, Issuse1, 1997, p. 33-46. 